\title{
A 24.6-GHz MMIC HBT Triple-Push Oscillator
}

\author{
Yu-Lung Tang and Huei Wang \\ Dept. of Electrical Engineering and Graduate Institute of Communication Engineering, \\ National Taiwan University, Taipei, Taiwan, 10617, ROC \\ E-mail: hueiwang@ew.ee.ntu.edu.tw
}

\begin{abstract}
A triple-push oscillator has been implemented using MMIC approach. This 24.6-GHz MMIC HBT triple-push oscillator was fabricated using InGaP/GaAs HBT MMIC technology. The principle of a triple-push oscillator is that three identical fundamental oscillators are combined via microstrip-lines and operated in odd-mode oscillation to provide $120^{\circ}$ phase difference among three fundamental oscillators. As a consequence, the third harmonic signals of this MMIC triple-push oscillator chip were in-phase added to provide an output signal of $-14.8 \mathrm{dBm}$ at $24.6 \mathrm{GHz}$ with more than 20-dB fundamental and the second harmonic rejection.
\end{abstract}

\section{INTRODUCTION}

High frequency signal sources are crucial components in microwave and millimeter-wave (MMW) systems, especially needed for communication systems, radar systems, advanced imaging, and remote sensing applications. In the past, most of the high frequency oscillators are based on the conventional fundamental frequency oscillator approach, which has the drawback of insufficient device gain as frequency goes higher, such as millimeter-wave frequency range. To overcome the disadvantage, push-push oscillators comprising two fundamental oscillators, whose fundamental output signals are out-of-phase to each other, have been proposed [1]-[5]. In a push-push oscillator, two out-of-phase fundamental signals cancel out themselves and the second harmonic signals are combined in phase. As a consequence, the fundamental frequency is half the output frequency and more device gain can be used to generate a fundamental oscillator.

Extending from the push-push oscillator approach, the triple-push oscillator approach was proposed in [6]. As shown in Fig. 1, a triple-push oscillator comprising three symmetric oscillators, whose fundamental currents have $120^{\circ}$ phase difference to one another, can push the output frequency to triple the fundamental frequency due to in-phase combining of the third harmonic signals. Therefore, the triple-push oscillators allow the extension of the usable frequencies to a higher range rather than the fundamental and the push-push ones.

\section{CIRCUIT DESIGN}

The 24.6-GHz triple-push oscillator chip was fabricated using commercial InGaP/GaAs HBT MMIC technology on 4-mil GaAs substrates. The HBT devices have a typical unit current gain frequency $\left(f_{T}\right)$ of $32 \mathrm{GHz}$ and a maximum oscillation frequency $\left(f_{\max }\right)$ of $60 \mathrm{GHz}$. The recommended operating current density was from $1 \mathrm{kA} / \mathrm{cm}^{2}$ to $25 \mathrm{kA} / \mathrm{cm}^{2}$. In this chip, three InGaP/GaAs HBTs with emitter size of $1.4 \mu \mathrm{m} \times 9 \mu \mathrm{m}$ were used. 
Figure 2 illustrates the schematic diagram of one fundamental oscillator. The complete triple-push oscillator is combined with three fundamental oscillators via microstrip-lines. The chip photo is shown in Fig. 3 with chip size of $1.4 \mathrm{~mm} \times 1.25 \mathrm{~mm}$. The common collector configuration using $1.4 \mu \mathrm{m} \times 9 \mu \mathrm{m}$ HBT devices was chosen for its excellent instability. An emitter capacitor and collector inductors and were used to induce negative resistance looking into its base. In addition, a resonator connected to base was formed by a capacitor in series with an inductor for determining the oscillation frequency. An emitter degeneration resistor is employed to stabilize the dc biasing due to the temperature variation.

In a triple-push oscillator, two current modes can exist as described in [6]. In the small signal analysis, this circuit was designed to excite the odd mode currents at $9 \mathrm{GHz}$, but to quench the even mode. The time domain analysis was performed using Gammel-Poon models supplied by the MMIC foundry. As shown in Fig. 4 (a), the odd mode currents $\left(I_{1}, I_{2}, I_{3}\right)$ before combining have $120^{\circ}$ phase difference to one another so that after combining the third harmonic signals combine in phase and the fundamental and the second harmonic signals cancel themselves out. Periods of $I_{1}$, $I_{2}$, and $I_{3}$ are 112 ps (frequency $8.9 \mathrm{GHz}$ ). Fig. 4 (b) shows the output signal current waveform $\left(I_{\text {out }}\right)$ with period $37 \mathrm{pS}$ and hence frequency $26.7 \mathrm{GHz}$, which is triple the fundamental frequency.

\section{MEASUREMENT}

The MMIC chip was measured via on-wafer probing. The performance of one fundamental oscillator was measured with the other two turned off first. As the self-bias voltage $\mathrm{V}_{\mathrm{cc}}$ was fixed at $8.8 \mathrm{~V}$ of one fundamental oscillator, the center frequency was $7.1 \mathrm{GHz}$ with $-17-\mathrm{dBm}$ output power and the output power of the second and the third harmonic signals were $-31.5 \mathrm{dBm}$ and -33 $\mathrm{dBm}$. The inconsistence between the measured $(7.1 \mathrm{GHz})$ and the simulation fundamental $(8.9 \mathrm{GHz})$ frequencies may be due to the pulling effects and undetermined impedances of the two other oscillators being turned off.

The complete triple-push function was then tested. While three fundamental oscillators were all turned on at the same bias, this circuit exhibits a measured center frequency at $28.4 \mathrm{GHz}$ with output power of $-15.4 \mathrm{dBm}$, while the output power of the fundamental and the second signals were suppressed to $-21 \mathrm{dBm}$ and $-34 \mathrm{dBm}$, as shown in Fig. 5. Low fundamental signal suppressions in measurement may be due to the process variation of active devices and lumped elements as well as the unsymmetrical combining structure. These discrepancies may result in phase shifts of fundamental frequency signals in each subcircuit different from $120^{\circ}$, thus the fundamental frequency and the second harmonic signals can not be cancelled completely.

To optimize the circuit performance, the bias of each fundamental oscillator was adjusted such that better symmetry of phase difference can be obtained. After bias tuning, the circuit exhibited a measured center frequency at $24.6 \mathrm{GHz}$ with output power of $-14.8 \mathrm{dBm}$. The output power of the fundamental and the second signals were all suppressed below $-37 \mathrm{dBm}$. Figure 6 illustrates the spectrum plot of the triple-push oscillator MMIC after bias tuning. The output power of this oscillator is low due to the small size of devices $(1.4 \mu \mathrm{m} \times 9 \mu \mathrm{m}$ emitter area) used in the MMIC chip. 


\section{SUMMARY}

A MMIC oscillator using the triple-push oscillator approach has been designed, fabricated and tested. This HBT MMIC delivered a $-14.8-\mathrm{dBm}$ output power by combing three in-phase third harmonic signals at $24.6 \mathrm{GHz}$ due to triple-push principle. More than 20-dB fundamental and second harmonic rejections were achieved owing to $120^{\circ}$ phase difference among three fundamental oscillators.

\section{ACKLEDGEMENT}

This work is supported in part by National Science Council, (contract number: NSC 89-2219-E-002-042, and NSC 89-2213-E-002-178). The authors would like to thank Dr. Ying-Zung Juang for his coordinating all affairs of the foundry service provided by Global Communication Semiconductors (GCS) and accessed through Chip Implementation Center (CIC) of National Science Council (NSC) in Taiwan, and Shu-Fen Wei for her help of chip testing.

\section{REFERENCES}

[1] D. M. Smith, J. C. Canyon, and D. L. Tait, "25-42GHz GaAs hetero-junction bipolar transistor low noise push-push VCO's," 1989 IEEE MTT-S International Microwave Symposium Digest, Long Beach, California, June, pp. 78-81, 1989.

[2] F. X. Sinnesbichler, H. Geltinger, G. R. Olbrich, “A 50 GHz SiGe HBT push-push oscillator," 1992 IEEE MTT-S International Microwave Symposium Digest, Anaheim, CA, June, pp. 9-12, 1999.

[3] F. X. Sinnesbichler et al, "A Si/SiGe HBT dielectric resonator push-push oscillator", 2000 IEEE Microwave and Guided Wave Letter, pp. 145-147, Apr. 2000.

[4] K. W. Kobayashi, J. Cowles, L. T. Tran, A. Guiterrez-Aitken, T. Block, F. Yamada, A. K. Oki, and D. C. Streit, “A low phase noise W-band InP-HBT monolithic push-push VCO,” 20th Annual IEEE GaAs IC Symposium Digest, pp. 237-240, Atlanta, GA, Nov. 1998.

[5] F. X. Sinnesbichler, H. Geltinger, and G. R. Olbrich, “A 38-GHz push-push oscillator based on 25-GHz $f_{T}$ BJT's," IEEE Microwave and Guided Wave Letter, vol. 9, no. 4, pp. 151-153, Apr., 1999.

[6] Yu-Lung Tang and Huei Wang, "A Novel triple-push oscillator approach," 2000 IEEE MTT-S International Microwave Symposium Digest, Boston, MA, vol.2, pp. 1201-1204, June 2000.

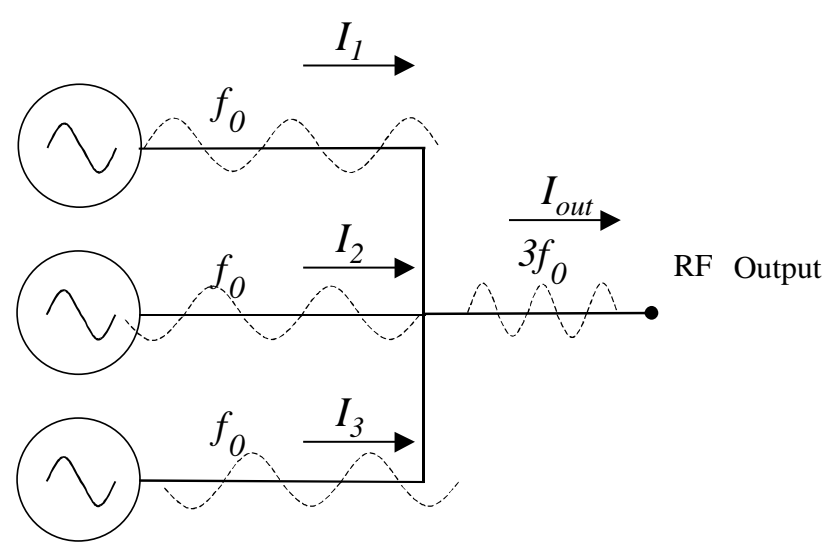

Fig. 1 A general triple-push-oscillator architecture with depicting currents behavior.

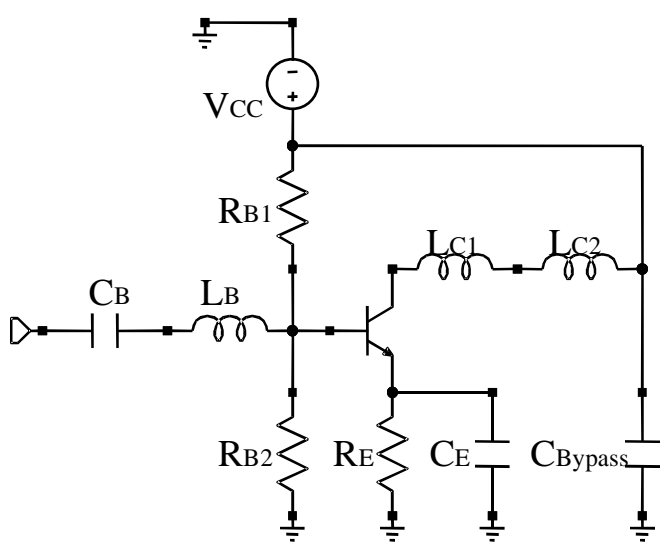

Fig. 2. Schematic diagram of one fundamental oscillator of the 24.6-GHz HBT triple-push oscillator. 


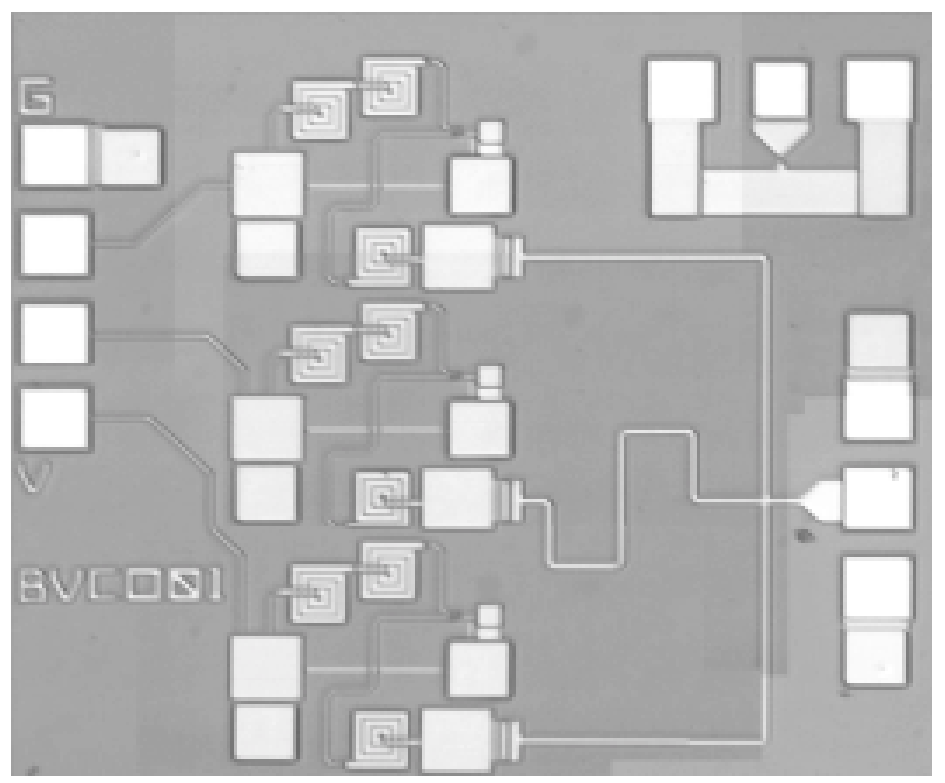

Fig. 3. Chip photo of the 24.6-GHz HBT triple-push oscillator MMIC with chip size of $1.4 \mathrm{~mm} \times 1.25 \mathrm{~mm}$.

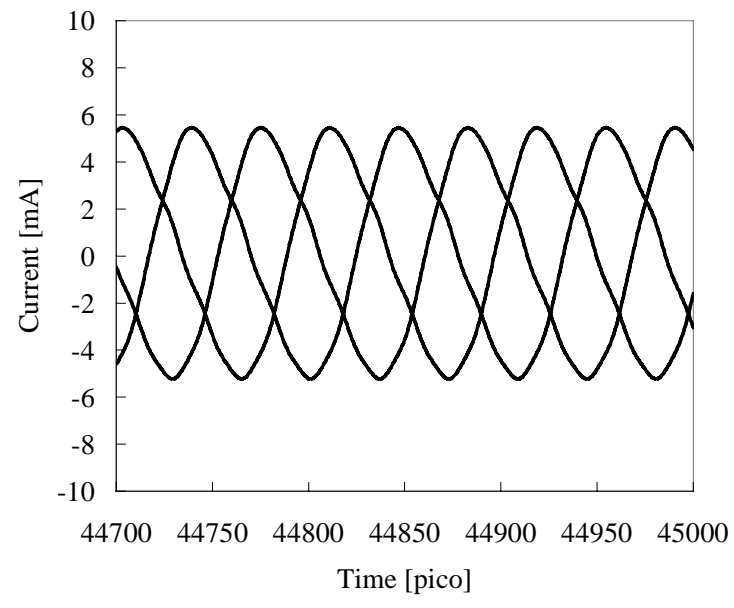

(a)

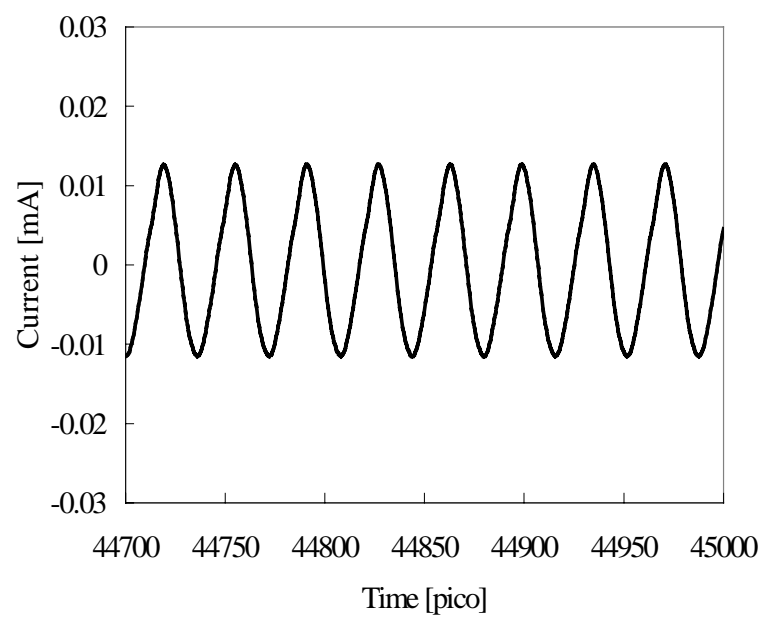

(b)

Fig. 4 (a) Simulated current waveforms $I_{1}, I_{2}$, and $I_{3}$ and (b) simulated current waveform $I_{\text {out }}$.

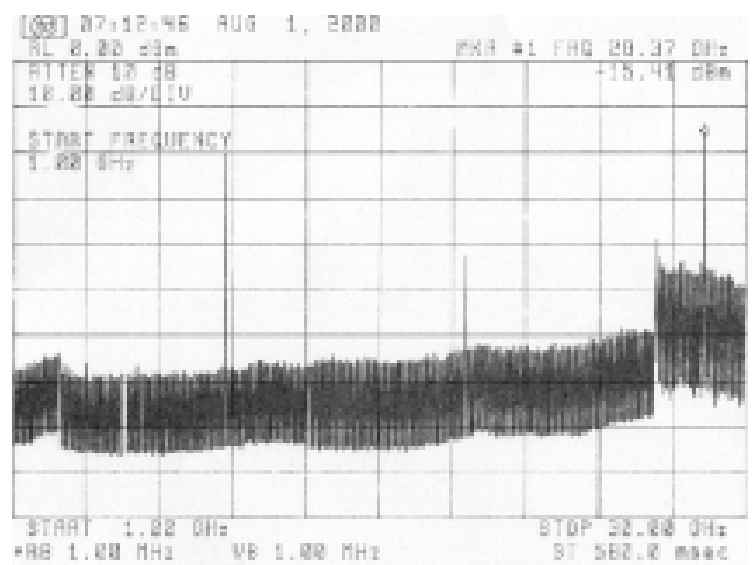

Fig. 5 Measured spectrum of the triple-push oscillator MMIC before the bias tuning.

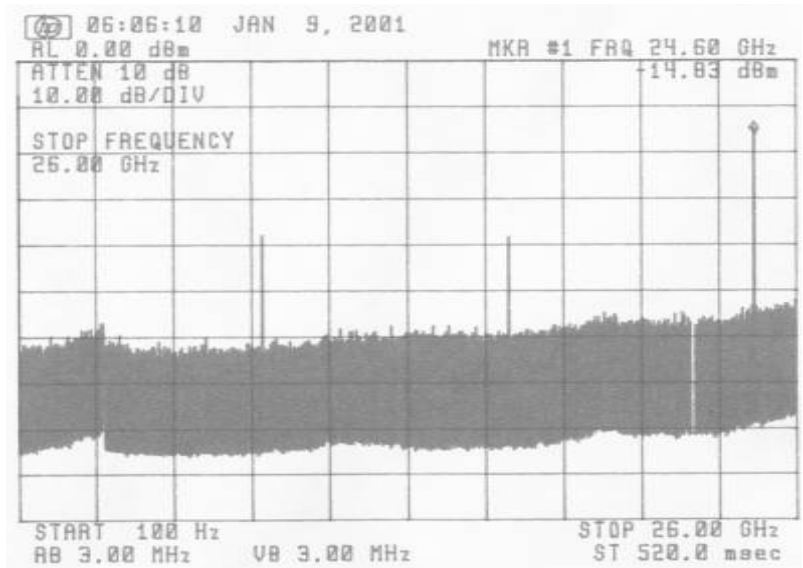

Fig. 6 Measured spectrum of the triple-push oscillator MMIC after the bias tuning. 